\title{
Acute intussusception on a lipoma of the left colon: report of a case
}

\author{
Rafik Ghrissi, Mohamed Habib Belhajkhlifa, Mohamed Amine Elghali, Mohamed Saleh Jarrar, Fehmi Hamila, \\ Mohamed Rached Letaief \\ Department of General Surgery, Farhat Hached University Hospital, Tunisia
}

Received: November 8, 2015

DOI: $10.5430 / j b g c . v 6 n 1 p 20$
Accepted: November 24, $2015 \quad$ Online Published: November 27, 2015

URL: http://dx.doi.org/10.5430/jbgc.v6n1p20

\begin{abstract}
Introduction: Lipomas of the colon are rare benign tumors. Colo-colonic intussusception caused by colonic lipoma is more rare. Case report: We report a case of a 52-year-old patient presenting with recurrent colonic obstruction which occurred in recent days. Colonoscopy revealed a large submucosal mass having benign appearance. Abdominal computed tomography scan diagnosed colo-colonic intussusception due to a large lipoma of the sigmoid colon. Diagnosis was confirmed during operative reduction and resection. He had segmental left colectomy. The postoperative course was uneventful.

Conclusion: Computed tomography scan and colonoscopy seem important for diagnosing both lipoma and intussusception. The treatment may be surgical or endoscopic.
\end{abstract}

Key Words: Colonic lipoma, Intussusception, CT scan, Treatment

\section{INTRODUCTION}

Intussusception is rare in adults. It represents less than $5 \%$ of acute intestinal obstruction. It affects the small intestine in $\frac{3}{4}$ of cases and colon in $\frac{1}{4}$ of cases. ${ }^{[1]}$ Unlike in children, the symptomatic intussusception in adults is often secondary to a malignant organic lesion. Rarely, it can be a benign tumor and much more rarely colonic lipoma.

\section{OBSERVATION}

A man aged 52 years with a history of hypertension and renal failure at the stage of hemodialysis, was admitted for recurrent bowel obstruction, occurring over the course of several days. Colonoscopy was conducted and a large polyp was found in the left colon. The abdominal computed tomography scan performed subsequently, diagnosed colo-colonic intussusception due to a large lipoma of the sigmoid colon (see Figure 1).

Surgical treatment was retained. Surgical exploration revealed a soft $3 \mathrm{~cm}$ colonic intraluminal mass, causing colocolonic intussusception. This is in favor of colonic lipoma; segmental colectomy with colorectal anastomosis was performed (see Figure 2). The postoperative course was uncomplicated. Pathology confirmed lipoma without signs of malignancy.

\section{Discussion}

Intussusception is more common in children than in adults. Indeed, adult intussusception constitutes less than $5 \%$ of all cases of intussusceptions and 1\%-3\% of all cases of intestinal obstruction. ${ }^{[2]}$ It affects small bowel in $48 \%-70 \%$ of cases, both ileum and caecum in $25 \%-40 \%$ of cases, and colon

\footnotetext{
*Correspondence: Rafik Ghrissi; Email: ghrissirafik@yahoo.fr; Address: Department of Surgery, Farhat Hached University Hospital, Ibn aljazzar Street 4000 Sousse, Tunisia.
} 
alone in only $5 \%-8 \%$ of cases. ${ }^{[3]}$ Unlike in the child where symptomatic intussusception is almost always idiopathic, in adults symptomatic intussusception is most frequently secondary to an endo-luminal lesion. ${ }^{[1]}$ These lesions are often carcinoma; rarely, it may be benign tumors. ${ }^{[3]}$ Adenomas are the most common colonic benign lesions, while colonic lipomas are less common. ${ }^{[1]}$ They constitute $10 \%$ of benign tumors of the digestive tube and $2 \%$ to $4 \%$ of colon benign tumors. ${ }^{[3]}$ In theory lipomas can reach the entire digestive tract from the hypopharynx to the rectum. In the colon, they are more common in the caecum and ascending colon and more rare in the left colon. ${ }^{[4]}$ Colonic lipomas affect mostly women between 50 and 70 years and are often solitary and submucosal. ${ }^{[4]}$ They often remain asymptomatic. ${ }^{[5]}$ For that reason, they are, usually, incidentally identified during imaging studies, colonoscopy, surgery or autopsy. ${ }^{[4,6]}$ Though symptoms are rare, they are more frequent with large pedunculated lipomas (larger than $3 \mathrm{~cm}$ ).

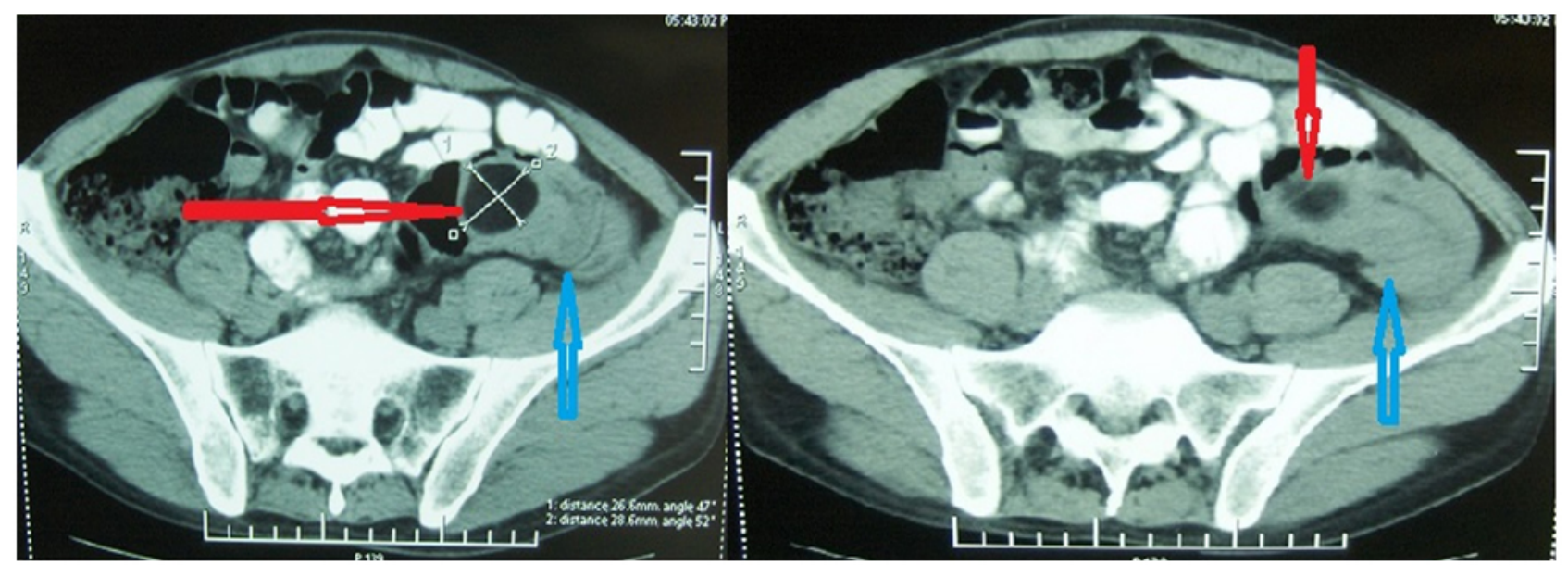

Figure 1. CT scan showing hypodense intraluminal mass (fat density) of the sigmoid colon (red arrows), and colo-colonic intussusception (blue arrows)

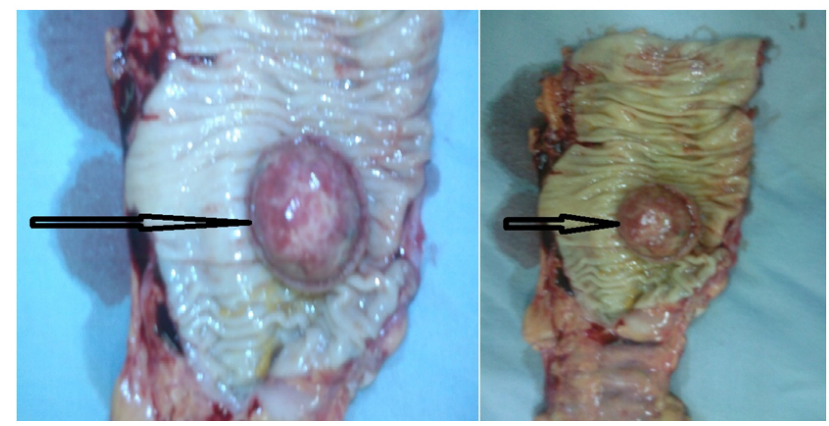

Figure 2. Surgical specimen of segmental colectomy showing endoluminal lipoma (black arrows)

Symptoms include abdominal pain, irregular rectal bleeding, anemia and digestive disorders (constipation, diarrhea). Exceptionally, the lipoma may be responsible for acute intussusception. ${ }^{[7]}$ Indeed in a series of 27 cases of intussusception published by Leon et al., only one case of colonic lipoma was reported. ${ }^{[1]}$ In addition, over a period of 45 years, only 46 cases of colonic intussusception secondary to colonic lipomas have been reported in the English language literature. ${ }^{[5]}$ Clinically, symptomatic intussusception presents as an acute intestinal obstruction. Recurrent bowel obstruction may occur due to intermittent spontaneous reduction and Published by Sciedu Press re-intussusception, as was the case with this patient. ${ }^{[1,3,8]}$

The differential diagnosis includes malignant tumor. This distinction is crucial in order to adopt proper treatment. However, this distinction is not always obvious and the definitive diagnosis will be made on histological examination of surgical specimen.

Ultrasonography may be able to diagnose intussusception and lipoma. However, in adults, its performance is limited by the interposition of bowel gas and the corpulence of the patient. Sonographic findings of intussusception include the "target sign" and "pseudo kidney sign". Lipoma is in the form of a regular hyperechogenic lesion surrounded by normal intestinal wall. ${ }^{[9]}$

CT is highly sensitive and specific in the diagnosis of intussusception, demonstrating a "bowel within bowel" appearance and associated bowel obstruction. In cases of intussusception due to lipoma, CT will show central fat density within the intussusceptum. ${ }^{[8]}$

Endoscopy identifies the soft tumor covered with normal mucosa, and it allows for biopsies.

Faced with symptomatic lipoma, treatment is the rule. Two options are possible: endoscopic resection or surgical exci- 
sion. Jiang et al. examined this issue in five aspects and recommended that endoscopic removal would not be appropriate in the following cases: 1) lipoma is larger than $4 \mathrm{~cm}$, sessile or has a limited pedicle, 2) malignancy is suspected, 3 ) intussusception is present, 4) it involves the muscular layer or serosa, 5) it cannot be radically removed at colonoscopy. ${ }^{[6]}$ Indeed, lipoma size and the size of its pedicle constitute the main limiting factors for the endoscopic resection, although there are publications in the literature reporting that lipomas with wide pedicles and large diameters may also be endoscopically removed. ${ }^{[10]}$ So, in the case of lipoma with intussusception, surgery is the rule; there is no place for endoscopic excision or air-enema reduction. ${ }^{[3]}$ The standard treatment for large, symptomatic or complicated lipomas is surgical with colectomy and primary anastomosis, as in this case. Colectomy with lymphadenectomy will be indicated if there are malignancy stigmas.

\section{Conclusion}

Symptomatic intussusception is rare in adults, and colonic lipoma is rarely the cause. In these rare cases, CT is important for diagnosis as it clearly demonstrates the presence and location of intussusception and the fat-density of the lipoma.

\section{CONFlicts OF INTEREST Disclosure}

The authors declare that they have no conflicts of interest.

\section{REFERENCES}

[1] Leon KE, John DC, Arthur HA Jr. Intussusception in Adults: Institutional Review. J Am Coll Surg. 1999; 188: 390-395. http: //dx.doi.org/10.1016/S1072-7515(98)00331-7

[2] Ongom PA, Kijjambu SC. Adult intussusception: a continuously unveiling clinical complex illustrating both acute (emergency) and chronic disease management. OA Emergency Med. 2013 August 01; 1,3. http://dx.doi.org/10.13172/2054-1902-1-1-647

[3] Abou-Nukta F, Gutweiler J, Khaw J, et al. Giant lipoma causing a colo-colonic intussusception. Am Surg. 2007; 73(4): 417.

[4] Arora R, Kumar A, Bansal V. Giant rectal lipoma. Abdom Imaging. 2011; 36: 545-547. PMid: 21153727. http://dx.doi .org/10.10 07/s00261-010-9668-7

[5] Paskauskas S, Latkauskas T, Valeikaite G, et al. Colonic intussusception caused by colonic lipoma: a case report. Medicina (Kaunas). 2010; 46(7): 477-481.
[6] Jiang L, Jiang LS, Li FY, et al. Giant submucosal lipoma located in the descending colon: a case report and review of the literature. World J Gastroenterol. 2007; 13: 5664-5667. http://dx.doi.org /10.3748/wjg.v13.i42.5664

[7] Wulff C, Jespersen N. Colo-colonic intussusception caused by lipoma. Acta Radiol. 1995; 36: 478-480. PMid: 7640090.

[8] Crozier F, Portier F, Wilshire P, et al. Diagnostic par scanner d'une invagination colocolique sur lipome du côlon gauche. Ann Chir. 2002; 127 : 59-61. http://dx.doi.org/10.1016/S0003-3944(01)0 0670-8

[9] Lebeau R, Koffi E, Diané B, et al. Invaginations intestinales aiguës de l'adulte: analyse d'une série de 20 cas. Ann Chir. 2006; 131: 447-450. PMid: 16765901. http://dx.doi.org/10.1016/j.a nchir.2006.04.007

[10] Jae ML, Jeong HK, Myung SK, et al. Endoscopic submucosal dissection of a large colonic lipoma: Report of two cases. World $\mathbf{J}$ Gastroenterol. 2015 March 14; 21(10): 3127-3131. PMid: 25780315. http://dx.doi.org/10.3748/wjg.v21.i10.3127 